\title{
Brand's Country-of-origin Effect on Demand for Hotels: An Exploratory Study
}

\author{
Giorgio Ribaudo
}

\begin{abstract}
The purpose of this study is to explore the effects of a brand's country-of-origin for a hotel on its geographic markets. The globalization of tourist markets has recently increased the importance of foreign demand for most European destinations, and the role of brands in attracting foreign demand is growing as a consequence. The brand is one of the key assets of multinational companies in tourism. Among the several determinants of consumer brand knowledge in the global competitive arena, country-of-origin (COO) effects remain among the most researched. Through an exploratory study, based on a survey of 95 branded hotels located in Italy belonging to 16 brands having USA, Spain, France and UAE as COO, we investigated the relationship between the hotel brand's $\mathrm{COO}$ and the top 5 geographic markets for the hotel. Our exploratory study demonstrates that in over $95 \%$ of cases the brand's COO market is one of the top 5 feeding markets for a hotel, thus indicating that, for a hotelier, choosing a certain hotel brand as franchisor or management company will significantly determine the geographic provenience of its hotel's guests..
\end{abstract}

KEY WORDS: $\quad$ Hotel chains; sales performance; country of origin; brand strategy

JEL Classification: $\quad$ Z32, Z30, O19

University of Bologna, Italy

\section{Introduction}

The brand is one of the key assets of multinational companies in tourism.

In one of its most accredited marketing and management manuals, Keller (2002) suggests that brands are intangible assets with a tangible financial value. Today, hotel companies are continuously exposed to decisions about affiliation to different kinds of brand, from corporate brands, to consortia brands and, more

Correspondence concerning this article should be addressed to Giorgio Ribaudo, University of Bologna, Via Angherà 22, Rimini, Italy.

E-mail: giorgio.ribaudo@unibo.it recently, even eco-label brands (Leroux \& Pupion, 2018).

In terms of the benefits that might accrue to hotel owners that choose brand affiliation, the literature suggests that hotel brand equity should be a strong motivating factor in this decision, as reported by Carvell et al. (2016). A positive relationship has been identified between brand equity and the financial performance of the brand-owning company (Kim, et al., 2003). Since hotel chains, as companies built on the axiom of brand recognition and exploitation, are increasing in number and their portfolio is constantly growing in size, several authors and the hospitality industry are questioning the real contribution of hotel chains under numerous standpoints. 
Official data from World Travel and Tourism Council (WTTC) highlights first, that international (nondomestic) hotel demand is increasing worldwide due to the recently gained ability of large portions of global population to access travel and leisure practices and, secondly, their strong willingness to visit major European destinations during their very first international travels. Some Authors have suggested markets globalization in tourism is fostered by the spread of international hotel chains (Montagner, 1997; Ivanov \& Ivanova, 2016) and their global strategies are increasing in effectiveness thanks to brand levering (Whitla et al, 2007).

Among the many factors influencing consumers' brand awareness, and therefore brands in the global era, country-of-origin (COO) remains the most researched one (Lim \& O' Cass, 2001; Al-Sulaiti \& Baker, 1998).

The study of literature indicates hotel chains have been largely investigated under different perspective, with the mainstream of scientific research concentrating on their international expansion and corresponding entry modes.

A less relevant line of research has, on the contrary, focused on investigating when and how affiliation to a hotel chain contributed to higher performance compared to independent operations.

Researches in this field, though limited to USA and UK, have concluded that chains contribution is not univocally positive, but varies according to the economic cycle of the country's tourism market (O’Neill, 2011), size and year of operations (Enz \& Canina, 2011) of the hotel.

Higher performance has never been associated with increased international demand by previous studies in the field of hospitality. Based on the approach developed through the application of network strategies to obtain scarce resources in the hotel industry (RevillaCamacho et al., 2019), we could argue that brands play a key role in attracting markets which are difficult to target due to geographic constraints or segmentation issues.

Nowadays, the industry is questioning the ability of hotel chains to generate additional international demand, and the brand's COO might be a determinant of such contribution.

Quoting Whitla et al., (2007) "a global brand allows consumers recognition worldwide and assurance regarding the range and quality of services that the hotel provides" (p. 783).

The current study explores the real impact of hotel chains on the international demand for hotels, now that the contribution of the international demand has become essential for the competitiveness of major European destinations. (e.g., in Spain in 2018, the share of international arrivals on total arrivals exceeded $50 \%$ according to Eurostat data).

A hotel can be defined as a "branded" when a professional organization owns, leases, manages, or franchises it and several other hotels, by means of centralized functions and under a central governance system, within its own strategic management guidelines and operational inputs (Peng \& Litteljohn, 1997; Litteljohn, 2003; Ribaudo \& Domeniconi, 2013). Often, a minimum size (three or five) is introduced for a hotel chain to be considered such (Ingram, 1996), considering that the economies of scale deriving from centralized services materialize starting from this minimum dimension (HVS, 2002; Ribaudo et al, 2014).

Brand equity in hospitality is one of numerous concepts of modern international marketing (Bailey \& Ball, 2006), but the brand impact on each single property can significantly differ, due to the factors which past literature has investigated as independent variables, such as the scale, size, economic cycle, life-cycle of a hotel, type (full vs. limited service), and so forth.

Brand's ability to expose a hotel to international markets is unquestionable. Nevertheless, since the appearance of third-party hotel distribution platforms such as the world-renowned Expedia, Booking, Travelocity, and Priceline, etc., promoting a hotel on a global scale is not anymore a prerogative of hotel chains.

Thus, the costs of being affiliated to a hotel chain, in terms of both fees and operational implications, is increasingly often compared by hospitality decision makers to the costs associated to on-line distribution. It is simply a matter of channel costs: how much does it cost to sell on international markets? Globalization and the appearance of highly promising markets (such as the Indian, Chinese, Russian, etc.) made being visible abroad more relevant and this is particularly true for top western Europe destinations, such as Spain, Italy, France (in 2015, the share of international hotel demand in terms of arrivals was $49 \%$ for Spain, $48.3 \%$ 
for Italy and $30.9 \%$ for France) which, for their tourism growth, highly rely on the international demand besides the (still relevant, but not growing) domestic demand. We have already introduced the importance of branding in the service industry from several perspectives. Especially the definition provided by Keller (2002) highlighted the notion that the brand is able to provide visibility, and consequently, sales to any business in the service industry and hospitality in particular.

It is widely recognized that hotel service delivery is perceived as less risky and volatile when provided by a branded property, following the implementation of standards and procedure put in place internationally for any affiliated hotel.

Brand trust, as observed, relates to both a company's perceived capability to consistently deliver on its quality commitments as well as its perceived intentions toward delivering on these commitments (Delgado-Ballester \& Munuera-Alemán, 2005). However, it is also argued that, in addition to a brand's halo effect, the values that individuals acquire in their cultural environment significantly influence their purchasing schemes and there are clear cross-country differences in consumers' value frameworks (Gomez-Suarez et al., 2019). In today globalized markets, brands are often purposely associated to geographic origins of certain consumer goods, a strategy that is intended to add perceived value to a product (Bustamante, 2019), but this type of view over brands' COO has yet very few antecedents.

Based on the evidences of the milestone study of Kaynak and Cavusgil (1983), who demonstrated that consumers tend to evaluate their own country's products more favorably than imported products, we have extended this axiom to hotel chains and brands: Are guests generally more attracted by brands originated in their home country when travelling abroad?

In hospitality, according to Carvell et al. (2016) brand affiliation helps to offset competition, thus achieving competitive advantage, reducing the effects of marketing actions of competitors, increasing the effectiveness of marketing communication activity, which results in greater profit (Keller, 2002).

The country of origin of a product is an important marketing element known to influence consumer perception as well as behavior. An improved understanding of how country of origin information influences guests' provenience is also valuable to marketing practitioners, for whom "quantification of brand equity" and "identification of elements that are likely to impact changes in consumer behavior and lead to changes in brand equity" are two important issues (Biel, 1993, p. 77).

The literature does not provide a satisfactory explanation for the factors influencing brand equity in the international context. Despite exhaustive research on brand equity over the past few decades, marketing literature does not fully explain how a change in the country of origin of a brand would affect its consumerbased equity. Neither is it clear whether the impact of country of origin on the consumer-based equity of a brand would be product-category specific. (Pappu, Genevieve, \& Cooksey, 2006).

Even in hospitality, the results of the limited set of studies are controversial. In China, for instance, the preference to western brands in luxury hospitality was not evident (Cathy H.C. Hsu, 2014), making it an unexpected result in comparison to previous studies in consumer goods.

There is a wide literature covering the impact of brands' COO ability to perform on certain markets (Elliott \& Cameron, 1994), but very few focus on hospitality (Suhartanto D., 2011), while most concentrate on tangible consumer goods. The availability of growing and accessible data on customer's purchasing preferences, including big data analytics on multitude of point of sales, has not yet shed light on brand's $\mathrm{COO}$ ability to orientate decisions of customers from several geographic markets, if we exclude certain categories of consumer goods (Chiang \& Yang, 2019).

Thus, how guests from different geographic markets formulate their preferences based on the brand's $\mathrm{COO}$ is still largely unknown.

Among the studies which speculate on this axiom within the hospitality industry, Lee, Haemoon and Hsu (2017), have benchmarked the brand's COO towards the decisions on the country of operations (international expansion). Chen (2005) uses the "country of origin" of the chain as a variable able to explain expansion theories and therefore considers its potential impact on chains' strategic choices.

Through a different approach, the Author of the current study uses the variable brand's COO to control the ability of a branded hotel to attract a specific market, 
specifically, the brand's country of origin market.

Previous studies provide evidence that hotel performance is dependent on the category (or scale, or segment) taken into account, we have included category as a control variable: O'Neill et al. (2006) showed that brands affected the market value of mid-price and upscale hotels beyond the usual contribution attributed to net operating income (NOI) and revenue per available room (RevPAR). In addition, Hanson et al. (2009) found performance improvements for hotels that rebranded to a higher market segment. Alternative evidence provided by other, numerous studies support the proposition that brand strength may not be uniform across hotel categories. Carvell (2016) have operated under the same assumption, match-pairing hotels based, also, on their category and their destinations.

Controlling according to destinations can provide additional robustness to the analysis, since it is possible to isolate the effect of brands' COO to the hotel, and the general importance of the country-of-origin for the destination where the hotel is located. As a consequence, we assumed category and destinations are the key pairing variables.

\section{Research Question, Hypotheses and Study Perimeter}

In another study (Ribaudo et al., in press), we have already presented the results of our research, comparing chains versus independent hotels based on international sales. We found that chain-affiliated hotels perform better than independent hotels in attracting foreign demand, and this is particularly true for international chains compared to domestic ones. The current study reinforces the previous study, by analyzing the ability of a brand to attract a specific market - the COO market. If our hypothesis is correct, this would add robustness to the thesis that affiliation to a brand provides hotels with a specific commercial attractiveness from, or exposure to, feeding markets where the brand was started. Following the goal of this study, research hypotheses are built in a way that should help the understanding of the outcome by industry players, that is hoteliers and hospitality (a) investors and (b) hotel chains.

The former would then be supported in evaluating affiliation opportunities, the latter would eventually gain evidence of their commercial success on international markets for the destinations where they are or where they consider to expand.

Previous studies covering hotel chains in Italy were based on partial data and avoided the examination of hotel chain performance due to the lack of performance data availability. What is the correct estimate of the phenomenon of hotel chains and brands in Italy and how can the industry read its impact is therefore the first important research question. Since the census carried out by the authors (Ribaudo \& Domeniconi , 2014) provides a platform to answer, it is then possible to investigate further on performance, controlling over business models, destinations, categories and brands headquarters, with the active support of hotel chains, which can be now sampled and surveyed.

Hoteliers would then be able to take decisions on affiliation also based on expectations deriving from the origin of the proposed brand, considering the category and type of destination where their hotel is located.

In fact, since the wide availability of affiliation options for hoteliers, and considering that the Italian market is pushed by international chains, who may have or may have not established a presence in the country yet, hoteliers should also consider if a brand is able to bring the desired additional foreign market. If the brand is allegedly bold to the market where it has first started (or where it was born, the COO), which is usually its headquarters country, then hotelier should be aware that, with a certain probability, that brand will improve sales to that market mostly.

All these considered, the research questions are:

Do branded hotels report significant volumes of demand from the brand's COO market?

Do they perform better than the competition in such a market?

The hotel system of the destination is the direct competition. Controlling through the destination can provide additional robustness to the evidence of the analysis, since we can isolate the effect of brands' COO to the hotel, isolating the general importance of the country-of-origin for the destination where the hotel is located.

As a consequence, we assume category and destinations are the key pairing variables.

Following this research questions, the study is meant to test the following hypothesis:

H1: Branded hotels have a higher share of the brand's $\mathrm{COO}$ market than the destination has: this 
would add robustness to the thesis that affiliation to a brand provides a hotel with a specific commercial attractiveness from, or exposure to, feeding markets where the brand was started, thus supporting H1.

To support the research hypothesis the study investigated the following:

1. First 5 markets for the branded hotel, to support the understanding of the correlation between the brand's $\mathrm{COO}$ and the most relevant markets for the affiliated hotel;

2. Ranking of international markets for all hotels, for each destination included in the survey, to infer the relevance of each market for the overall hotel system in the destination and to compare it with chain hotels evidence;

These areas of investigation will provide a structure to understand if a brand is able to attract more demand from a specific market, supposedly the COO market, than the destination itself does, both in terms of which markets and how important they are in terms of weight on the overall demand for the hotel.

\section{Research Design and Data}

The research was designed over 2 major pillars: the hotel chains census, carried out by the Author during the period 2012-2018 (Ribaudo et al., 2013), and the survey of chain hotels, conducted in 2016.

The investigated panel was composed of hotels belonging to chains through one of the four business models, for the year 2015 and 2016, or even 2016 only. Given the relevant size of the target panel, we have decided not to direct the survey to the single property, but rather to obtain the participation of the chain, by involving in the survey only the responsible person instead of the single chain property. This was meant to facilitate the response and obtain more reliable and comparable data, thus improving data accuracy.

For each hotel data collected were:

1. international arrivals, in absolute and percentage relative terms as share of total arrivals;

2. international arrivals from top 5 international markets.

Hotels have not been requested to provide data on their profiles, as the profiling was provided through the pre-filled part of the form, which was derived from the Census database. The survey form was then personalized and built on the expected participation for each hotel chain (owning several brands and several hotels under each brand). Following the scopes described, the investigated data were:

12015 and 2016 share of international arrivals (international arrivals / total arrivals)

2. 2015 and 2016 absolute value of international arrivals

3. 2015 and 2016 first 5 international arrivals source countries absolute values

Data relative to 2015 were meant to support a pilot study.

The hotels' population has been derived from the Hotel Chain Census 2017, filtering through the years 2016 and 2015 .

As mentioned, due to the peculiar kind of data requested and the confidential data disclosure policy of hotel chains, we have planned to target a convenience sample.

In the year of the survey, hotel chains were (as they are today) spread over more than 550 destinations (municipalities) in Italy. It was then impossible, as well as not necessary, to plan a survey intended to investigate all destinations and all chains (205 brands) for the cost and time this would have implied. We have then focused on top destinations in terms of highest concentration of hotel chains, with this assuring a greater response rate and high representativeness of results. We limited the survey perimeter to those destinations summing up to $60 \%$ of overall hotel population, resulting in 55 destinations.

The investigation of arrivals for each relevant destination was supported by secondary data, obtained from Italian Government Statistical Office (ISTAT).

The survey covered two years, 2015 and 2016: respondents were first asked to provide data for 2015, which were used as a pilot study and to determine optimal sampling size. They were then asked to provide complete data on international arrivals (all, in absolute and percentage value, and the top 5 markets arrivals in absolute values) for the 2016, the year on which the final research is based.

The study covered the year 2016 since the survey design started in late 2018 and, at that time, it was 
not possible to obtain data on the 2017 form hotel chains since most of them have not yet run yearly reporting.

In addition, ISTAT secondary data were not available yet for the 2017 year.

Before starting the survey, we checked 2016 for special events or contingencies which could have positively or negatively affected international flows to Italy in that period and found that nothing relevant could be assumed to create significant distortions for the scope of the study.

The research design has been driven by the necessity to compare two sub-set of hotels, branded hotels and independent hotels, according to a matched-pair methodology most recently adopted for such studies comparing performance among sets of hotels (Carvell, Canina, \& Sturman, 2016), thus accessing several data sources.

This model, specifically meant to explain how hotels' and chains' managers operate and articulate their business strategies, is particularly fit for the hospitality industry and has been treated in depth by several authors and in particular by Mathews (2000).

Several authors and industry practice, as confirmed by Mathews (2000), have highlighted that the study of competitors among hotels is based on three major metrics: price, segment, and proximity. Since using price to identify rivals can be, nowadays, problematic due to volatility of price, revenue management practices and channel mix which could differ among hotels, market segment and location are the clearest and more genuine ways to define competitive sets of hotels.

Although, as specified by the author, a clear way to measure proximity does not exist, a demand (guest) perspective can be used. So that hotels in Venice are assumed to compete to those located in Venice and not in Rimini, as hotels in London City are not directly competing with those in Henley on Thames, and so on, simply because they serve markets which are different in terms of specific location demanded. Furthermore, in his study, Mathews (2000) concludes that size (number of rooms) is not a relevant competitive metric, while, as opposite, being affiliated to a brand adds value to segmenting competitors and identifying the correct competitive set.

If we assume hotels in the same destination and scale compete against each other and may be compared in terms of performance, grouping among chain hotels and the whole hotel portfolio in the destination (which is a population of branded and unbranded hotels), then the affiliation itself will be a key pairing variable, in addition to destination and scale (Carvell et al., 2016).

Performance is then paired by destinations and scales, simply as dependent variable of the size of the hotel, assuming hotels of the same size should sell equal amount of rooms, thus making the available room the independent variable.

There might be several other independent variables to consider useful to enrich the presented model, many of which are considered in literature, such as the year of opening, the type of hotel, ADR, and so forth. But since the goal of the research is to compare performance among two subsets of the same population, by match-pairing them based on key variables, a more sophisticated model would not enrich the evidences obtained or their understanding. Moreover, the observations possible are far from being thousands (as for the cases of the American articles mentioned) and a more sophisticated model would block on the reduced robustness of limited sample.

We have extracted from the census those hotel chains (owning brands) with properties in the selected 55 destinations, with this surveying 157 brands of 43 chains. We obtained responses from 22 brands, for all their respective hotels in 21 destinations of the 55 surveyed, for 159 hotels (sample observations) out of the 420 existing (population) in these 21 destinations. Data cleaning was performed prior to panel analysis, which reduced the number of observations to 148 (35.2\% of the overall population of chain hotels in the 21 destinations), mainly due to destinations being not enough represented, to data not coherent, wrongly reported or uncomplete.

The descriptive statistics for the sample are presented in Table 1.

Given the new perimeter for the analysis was set around a population of 21 destinations, the estimate of the sample size was made according to the 
Table 1. Descriptive statistics indicating chain hotel population, surveyed destinations and responding sample

\begin{tabular}{|c|c|c|c|c|c|}
\hline $\begin{array}{c}\text { Descriptive } \\
\text { statistics } \\
\text { Population. and } \\
\text { Sample } \\
\end{array}$ & Destinations & HOTELS & $\%$ of Population & BRANDS & $\begin{array}{c}\text { Sample } \\
\text { Hotels }\end{array}$ \\
\hline $\begin{array}{l}\text { Chain Hotels (all } \\
\text { scales) - Italy }\end{array}$ & 430 & 1.322 & $100.0 \%$ & 183 & \\
\hline $\begin{array}{l}\text { Chain Hotels (3-4-5 } \\
\text { scales) - Italy }\end{array}$ & 430 & 1.313 & $100.0 \%$ & 183 & \\
\hline $\begin{array}{l}\text { Chain Hotels (3-4-5 } \\
\text { scales) - Surveyed }\end{array}$ & 55 & 796 & $60.6 \%$ & 157 & \\
\hline $\begin{array}{l}\text { Chain Hotels (3-4-5 } \\
\text { scales) - Responding }\end{array}$ & 21 & & & 22 & 159 \\
\hline $\begin{array}{l}\text { Number of } \\
\text { observations (after } \\
\text { data cleaning) }\end{array}$ & 21 & 420 & $32.0 \%$ & 22 & 148 \\
\hline
\end{tabular}

formula described by Cochran (1977) where the sample size is a function of the coefficient of variation (CV) obtained in a previous pilot study (2013 data in this case).

The CV, also known as relative standard deviation (RSD), is a standardized measure of dispersion, calculated as follows:

$\mathrm{CV}=\mathrm{s} / \ddot{\mathrm{X}}$

where $s$ is the standard error and is the average calculated on the values obtained is $\ddot{X}\llcorner$ pilot study. By calculating the $\mathrm{CV}$ and by knowing the size of the population, it is possible to estimate the minimum sample size to be taken, as follows:

$n=\left(\frac{s}{\bar{x}}\right)^{2} *\left(\frac{t_{a}^{2}}{r^{2}}\right) * 100^{2}$

where $t=1.96$ is the Student's $t$ value for the $95 \%$ $\mathrm{CI}$ for a normal distribution and $\mathrm{r}$ is the precision desired on the final estimation.

In order to understand if the sample size col- lected in 2014 was representative of the population, FmPAR (Foreign market Per Available Room) values collected for 2013 on the same population were employed as pilot study. Firstly, the normality distribution was tested by the Shapiro-Wilk test; as the data were not normally distributed, they were log-transformed. Secondly, their CV was calculated and a precision of $10 \%$ was fixed.

Following the previously described formula, the minimum sample size to be taken in the next survey results to be $n=57$.

Instead, the actual convenience sample size collected for elaborating on the year 2014 was $n=148$, which largely overpasses the minimal required sample size and ensures a precision of $6 \%$ on the final estimates, which is completely satisfactory for the scope of this research and the transferability of results to chains population in the 21 destinations explored.

Table 2 shows the application of this calculus to the chain hotels population in the 21 destinations. 
Table 2. Descriptive statistics for population and sample by observed destinations.

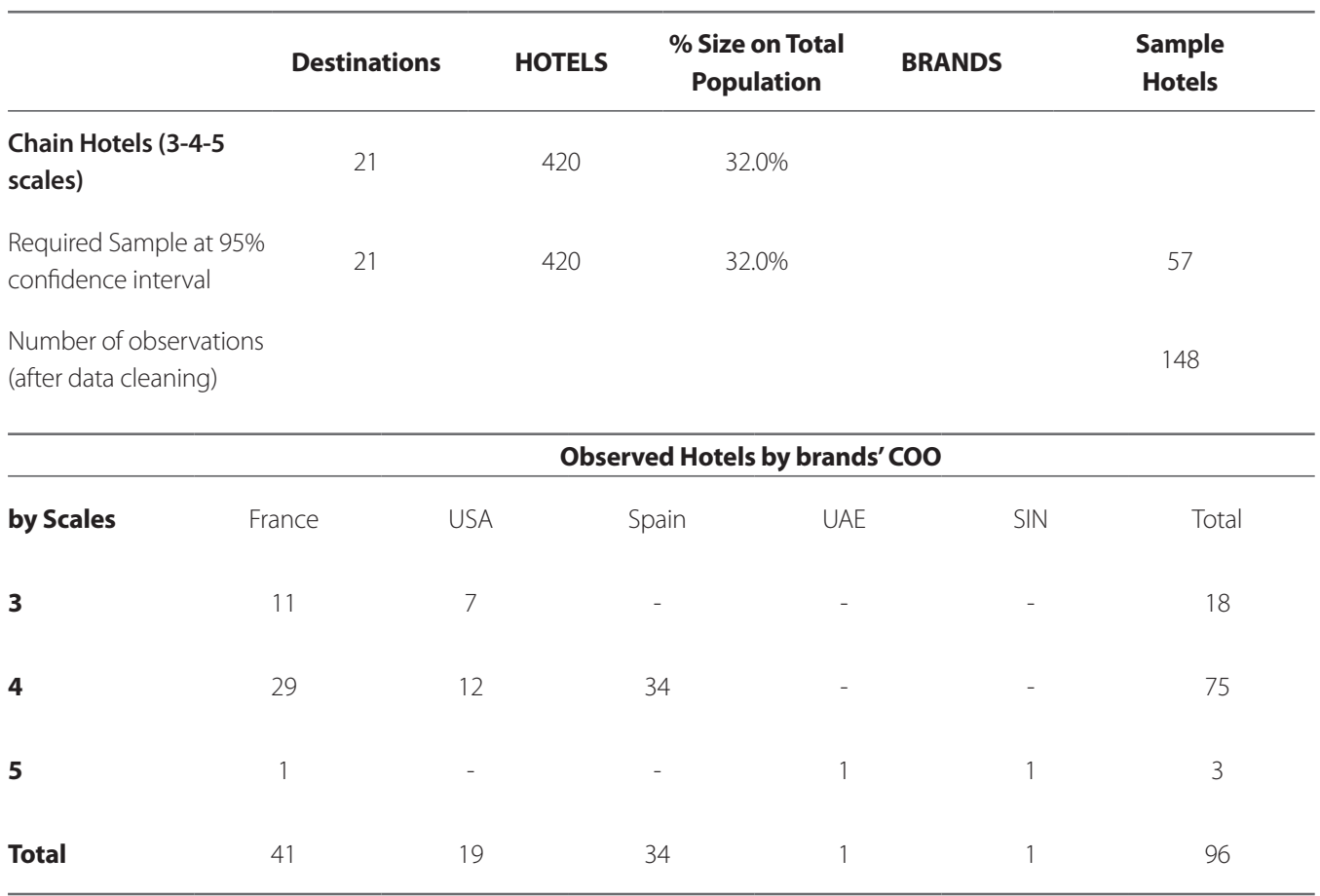

Of the 148 hotels belonging to 22 brands, 111 hotels $(75 \%)$ were in the four-star scale. The concentration of 4-star rooms observed on the whole is even higher, at $81 \%$. Nevertheless, this high percentage reflects the distribution of chain properties in the population at country level, where fourstar chain hotels are the majority, at $66 \%$, while threestar hotels are $23 \%$ and five-star hotels were just $10 \%$. Hotels and rooms per each respondent brand are presented in the Table 3.

Finally, we considered to exclude hotels belonging to Italian chains (Ribaudo et al., 2014) due to the bias they could create in examining the evidence based on foreign arrivals. Thus, we reduced the observations to 96 hotels branded by international operators/franchisors, whose brands' COO are reported in Table 4.

Finally, we considered to exclude hotels belonging to Italian chains (Ribaudo et al., 2014) due to the bias they could create in examining the evidence based on foreign arrivals. Thus, we reduced the observations to 96 hotels branded by international operators/franchisors, whose brands' COO are reported in Table 4.

\section{Data Analysis}

Foreign markets for sampled chain hotels were investigated with reference to their respective country head-quarter markets to demonstrate H1.

Table 5 indicates how many times, measured by frequencies, the brand's COO (named "Brand's country-of-origin" in the table) was found to be one of the first five markets for surveyed hotels and the mean value recorded for each of the five cases:

The results of the analysis indicated that for almost $95 \%$ of observations, the brand's COO is one of the key 5 markets for a hotel, while it is the first market for a hotel in 54\% circa of cases.

It is to be noticed, though, that the markets investigated as being brands' COO were USA, France, Spain (UAE was also one country included in the panel, but excluded from final results as covering 
Table 3. Respondent brands (including domestic), hotels and rooms in the sample.

\begin{tabular}{lccc}
\hline Brands in the Sample & Brands' COO & Sampled Hotels & Sampled Rooms \\
\hline NH Hotels & Spain & 27 & 4.986 \\
Mercure by Accor & France & 21 & 2.174 \\
UNA Hotels \& Resorts & Italy & 19 & 1.862 \\
Best Western & USA & 12 & 840 \\
Novotel by Accor & France & 11 & 1.958 \\
Rimini Residence & Italy & 10 & 347 \\
Ibis by Accor & France & 8 & 1,519 \\
JSH & Italy & 8 & 948 \\
Mgallery By Sofitel & France & 8 & 765 \\
NH Collection & Spain & 6 & 907 \\
Ibis Style by Accor & France & 4 & 459 \\
Best Western Plus & USA & 2 & 201 \\
Best Western Premiere & USA & 2 & 187 \\
Ramada & USA & 2 & 318 \\
Unaway & Italy & 2 & 363 \\
Adagio Aparthotels & France & 1 & 107 \\
Aman Resorts & Singapore & 1 & 24 \\
Clarion Collection & USA & 1 & 69 \\
Jumeirah & UAE & 1 & 116 \\
NHow & Spain & 1 & 246 \\
Sofitel & France & 1 & 81,477 \\
Total & & 148 &
\end{tabular}

Table 4. Sampled hotels by brands' COO (excluding domestic brands).

\section{Sample hotels by brands' $\mathrm{COO}$}

\begin{tabular}{|c|c|c|c|c|c|c|}
\hline by Scales & France & USA & Spain & UAE & SIN & Total \\
\hline 3 & 11 & 7 & - & - & - & 18 \\
\hline 4 & 29 & 12 & 34 & - & - & 75 \\
\hline 5 & 1 & - & - & 1 & 1 & 3 \\
\hline Total & 41 & 19 & 34 & 1 & 1 & 96 \\
\hline
\end{tabular}


Table 5. Presence of the brand's $\mathrm{COO}$ among the top 5 markets for surveyed hotels and mean of the brand's COO Market Share.

Brand's

\section{Foreign markets in surveyed hotels - Ranking of markets}

\begin{tabular}{lcccccccc} 
CoO & 1st & 2nd & 3rd & 4th & 5th & $\begin{array}{c}\text { Top 5 } \\
\text { markets }\end{array}$ & $\begin{array}{c}\text { Rest of } \\
\text { markets }\end{array}$ & Total \\
\hline Frequencies & $53,7 \%$ & $21,1 \%$ & $9,5 \%$ & $6,3 \%$ & $4,2 \%$ & $94,8 \%$ & $5,2 \%$ & $100 \%$ \\
Mean Value & $26,3 \%$ & $16,6 \%$ & $9,3 \%$ & $8,5 \%$ & $6,3 \%$ & \\
\hline
\end{tabular}

Table 6. Relative importance of brands' Country Of Origin each destination, for surveyed hotels ( $\mathrm{Fm} \mathrm{CH}_{\mathrm{H}} \%$, Share of Foreign Market for Chain Hotel) and for the overall destination ( $\mathrm{Fm}_{\mathrm{PH}} \%$, Share of Foreign Market for the Destination), for four and five star observations.

\begin{tabular}{|c|c|c|c|c|}
\hline Destination & 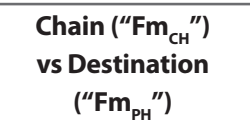 & Brands' COO 1 & Brands' $\mathrm{COO} 2$ & Brands' $\mathrm{COO} 3$ \\
\hline \multirow{2}{*}{ Bergamo } & Chain & $10 \%$ & $30 \%$ & \\
\hline & Destination & $7 \%$ & $9 \%$ & \\
\hline \multirow{2}{*}{ Bologna } & Chain & $14 \%$ & $25 \%$ & \\
\hline & Destination & $7 \%$ & $7 \%$ & \\
\hline \multirow{2}{*}{ Brescia } & Chain & $14 \%$ & $27 \%$ & \\
\hline & Destination & $11 \%$ & $4 \%$ & \\
\hline \multirow{2}{*}{ Catania } & Chain & $35 \%$ & & \\
\hline & Destination & $14 \%$ & & \\
\hline \multirow{2}{*}{ Florence } & Chain & $12 \%$ & $26 \%$ & \\
\hline & Destination & $5 \%$ & $5 \%$ & \\
\hline \multirow{2}{*}{ Genoa } & Chain & $21 \%$ & $29 \%$ & \\
\hline & Destination & $16 \%$ & $5 \%$ & \\
\hline \multirow{2}{*}{ Milan } & Chain & $19 \%$ & $7 \%$ & $26 \%$ \\
\hline & Destination & $7 \%$ & $8 \%$ & $4 \%$ \\
\hline \multirow{2}{*}{ Naples } & Chain & $31 \%$ & $38 \%$ & $4 \%$ \\
\hline & Destination & $11 \%$ & $5 \%$ & $13 \%$ \\
\hline \multirow{2}{*}{ Padua } & Chain & $20 \%$ & & \\
\hline & Destination & $3 \%$ & & \\
\hline \multirow{2}{*}{ Palermo } & Chain & $27 \%$ & & \\
\hline & Destination & $13 \%$ & & \\
\hline \multirow{2}{*}{ Parma } & Chain & $18 \%$ & & \\
\hline & Destination & $14 \%$ & & \\
\hline \multirow{2}{*}{ Pescara } & Chain & $14 \%$ & & \\
\hline & Destination & $9 \%$ & & \\
\hline \multirow{2}{*}{ Rimini } & Chain & $7 \%$ & & \\
\hline & Destination & $5 \%$ & & \\
\hline \multirow{2}{*}{ Rome } & Chain four star & $23 \%$ & $6 \%$ & $21 \%$ \\
\hline & Destination four star & $4 \%$ & $25 \%$ & $6 \%$ \\
\hline
\end{tabular}


Table 6. Relative importance of brands' Country Of Origin each destination, for surveyed hotels ( $\mathrm{Fm} \mathrm{CH}_{\%}$, Share of Foreign Market for Chain Hotel) and for the overall destination ( $\mathrm{Fm}_{\mathrm{PH}} \%$, Share of Foreign Market for the Destination), for four and five star observations (Continued).

\begin{tabular}{|c|c|c|c|c|}
\hline Destination & $\begin{array}{c}\text { Chain ("Fm }{ }_{\mathrm{CH}} \text { ") } \\
\text { vs Destination } \\
\text { ("F- }{ }_{\mathrm{PH}} \text { ") }\end{array}$ & Brands' COO 1 & Brands' $\mathrm{COO} 2$ & Brands' $\mathrm{COO} 3$ \\
\hline \multirow{2}{*}{ Rome } & Chain five star & $15 \%$ & $6 \%$ & \\
\hline & Destination five star & $6 \%$ & $0,2 \%$ & \\
\hline \multirow{2}{*}{ Siena } & Chain & $21 \%$ & & \\
\hline & Destination & $4 \%$ & & \\
\hline \multirow{2}{*}{ Turin } & Chain & $43 \%$ & $7 \%$ & $29 \%$ \\
\hline & Destination & $13 \%$ & $12 \%$ & $4 \%$ \\
\hline \multirow{2}{*}{ Venice } & Chain & $13 \%$ & $16 \%$ & $20 \%$ \\
\hline & Destination & $7 \%$ & $16 \%$ & $3 \%$ \\
\hline Mean Value & Chain & $19,8 \%$ & $19,7 \%$ & $20,0 \%$ \\
\hline Std.Dev. & $\left(" \mathrm{Fm}_{\mathrm{CH}} \% "\right)$ & $9,3 \%$ & $11,7 \%$ & $9,7 \%$ \\
\hline Mean Value & Destination & $8,7 \%$ & $8,8 \%$ & $6,2 \%$ \\
\hline Std.Dev. & $\left(" \mathrm{Fm} \mathrm{PH}_{\mathrm{PH}} \%\right)$ & $4,0 \%$ & $6,8 \%$ & $3,9 \%$ \\
\hline
\end{tabular}

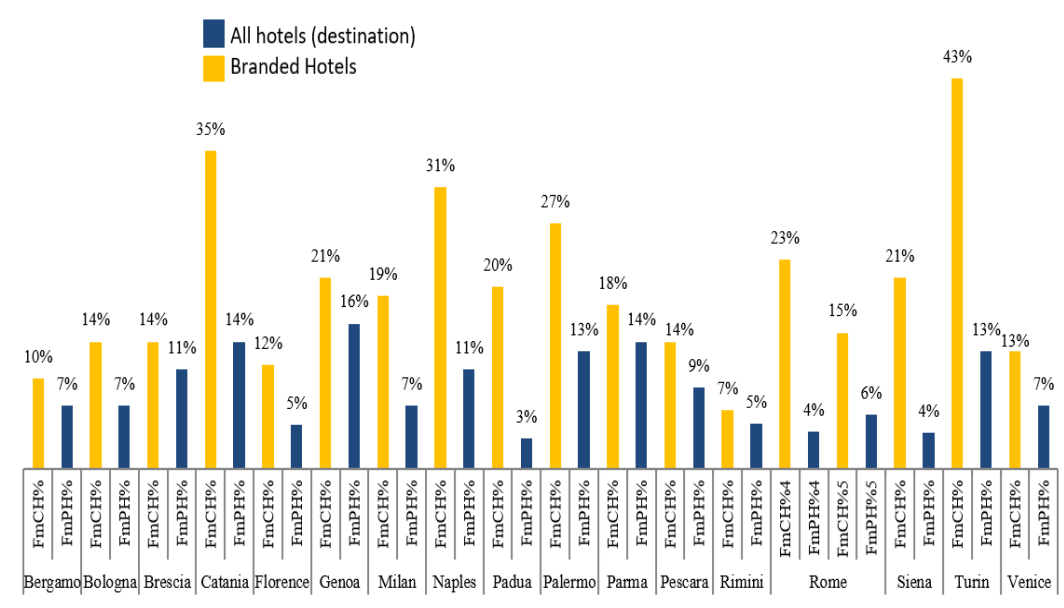

Figure 1. Relative importance of a brand's $\mathrm{COO}$ in each destination, for surveyed hotels $\left(\mathrm{Fm}_{\mathrm{CH}} \%\right)$ and for the overall destination ( $\left.\mathrm{Fm}_{\mathrm{PH}} \%\right)$, for four and five star hotels. 
Table 7. Relative importance of brands' $\mathrm{COO}$ for each destination, for surveyed hotels ( $\left.\mathrm{Fm}_{\mathrm{CH}} \%\right)$ and for the overall destination $\left(\mathrm{Fm}_{\mathrm{PH}}\right)$, for three-star observations.

\begin{tabular}{|c|c|c|c|}
\hline Destination & $\begin{array}{c}\text { Chain ("Fm }{ }_{\mathrm{CH}}{ }^{\prime \prime)} \\
\text { vs Destination ("Fm }{ }_{\mathrm{PH}} \text { ") }\end{array}$ & Brands' $\mathrm{COO} 1$ & Brands' $\mathrm{COO} 2$ \\
\hline \multirow{2}{*}{ Bologna } & Chain & $5,0 \%$ & \\
\hline & Destination & $7,0 \%$ & \\
\hline \multirow{2}{*}{ Catania } & Chain & $9,0 \%$ & \\
\hline & Destination & $4,6 \%$ & \\
\hline \multirow{2}{*}{ Florence } & Chain & $14,0 \%$ & \\
\hline & Destination & $7,0 \%$ & \\
\hline \multirow{2}{*}{ Genoa } & Chain & $7,0 \%$ & \\
\hline & Destination & $4,0 \%$ & \\
\hline \multirow{2}{*}{ Milan } & Chain & $12,0 \%$ & \\
\hline & Destination & $6,0 \%$ & \\
\hline \multirow{2}{*}{ Padua } & Chain & $15,0 \%$ & \\
\hline & Destination & $8,0 \%$ & \\
\hline \multirow{2}{*}{ Parma } & Chain & $17,0 \%$ & \\
\hline & Destination & $17,0 \%$ & \\
\hline \multirow{2}{*}{ Pescara } & Chain & $5,0 \%$ & \\
\hline & Destination & $7,0 \%$ & \\
\hline \multirow{2}{*}{ Rome } & Chain & $16,0 \%$ & \\
\hline & Destination & $8,0 \%$ & \\
\hline \multirow{2}{*}{ Turin } & Chain & $3,0 \%$ & \\
\hline & Destination & $6,0 \%$ & \\
\hline \multirow{2}{*}{ Venice } & Chain & $31,0 \%$ & \\
\hline & Destination & $13,0 \%$ & \\
\hline \multirow{2}{*}{ Verona } & Chain & $16,0 \%$ & $15,0 \%$ \\
\hline & Destination & $8,0 \%$ & $6,0 \%$ \\
\hline Mean Value & \multirow{2}{*}{$\mathrm{Fm}_{\mathrm{CH}} \%$} & $12,5 \%$ & $15,0 \%$ \\
\hline Std.Dev. & & $7,6 \%$ & --- \\
\hline Mean Value & \multirow{2}{*}{$\mathrm{Fm}_{\mathrm{PH}} \%$} & $8,0 \%$ & $6,0 \%$ \\
\hline Std.Dev. & & $3,6 \%$ & --- \\
\hline
\end{tabular}

1 only observation), which are all relevant markets for Italy, respectively the $2 \mathrm{nd}$, 3rd and 9th market in 2016.

The $\mathrm{Fm}_{\mathrm{CH}} \%$ (the share of foreign market for a chain hotel) mean value recorded in cases when the brand's COO is the first market is also very high at $26 \%$, meaning that, in more than half $(53.7 \%)$ of all observations, the brand's COO explains more than one quarter of overall international demand choosing the hotel.

Table 6 presents, for each destination and for the four and five stars categories ( 5 stars have been grouped with the 4 in the same table for the ease of reading, since only Rome provided observations for the 5 star scale), the resulting $\mathrm{Fm}_{\mathrm{CH}} \%$ (the share of foreign market for a chain hotel) value for sampled chain hotels vs $\mathrm{Fm}_{\mathrm{PH}} \%$ (the share of foreign market for a destination) of respective destinations, for each $\mathrm{COO}$ (named "Brands' COO 1", "Brands' COO 2", "Brands' COO 3").

For the ease of reading, data for the brands' $\mathrm{COO}$ are also presented in Figure1.

The four and five star surveyed hotels reported an 
average $20 \%$ (overall) of their respective brands' COO market, while the importance at destinations level of these same markets was $8 \%$ (overall). In other words, considering the foreign markets investigated (Spain, France, and USA), these explained, overall, an average $20 \%$ of international demand, for affiliated hotels (in the four- and five-star scale), while they explained just $8 \%$ of overall international demand for the destinations.

The same analysis is presented in Table 6 for the three-star hotels.

The analysis of three-star surveyed hotels against their respective destinations indicated that the brand's COO market is more relevant for the surveyed hotels (12.7\%) than it is for their destinations (7.8\%).

This evidence indicated that, on average, the $\mathrm{Fm}_{\mathrm{CH}}$ (Brand's $\left.\mathrm{COO}\right) \%$ is higher, even double, the $\mathrm{Fm}_{\mathrm{PH}}$ (Brand's COO)\%, so that the null hypothesis:

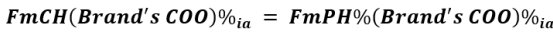

cannot be assumed to be true for the set of observations carried out, while it is demonstrated that:

FmCH $\left(\right.$ Brand $^{\prime}$ C COO $) \%_{i a}>$ FmPH $\%\left(\right.$ Brand $^{\prime}$ C COO $) \%_{i a}$

that is, for a chain hotel, the demand deriving from the country of origin of its brand is, for relative importance, superior to the destination's demand deriving from the same market.

Thus, the null hypothesis is rejected and $\mathrm{H} 1$ is assumed to be correct.

\section{Discussion}

Although being a relatively intuitive outcome of investigation, the link between the brand's $\mathrm{COO}$ and the most relevant markets for the branded hotel has never been investigated and confirmed before by means of data evidence.

The alleged correlation of the brand's COO and the first market for the branded hotel demonstrated to be very strong, with over half of observations having their first foreign market equivalent to their brand's $\mathrm{COO}$ market.

Although results might suffer the limitedness of the sample, when the similarity with the destination ranking of markets was controlled, it again indicated that brands have a clear impact in the amount of market brought to the hotel, which was by far higher than what averagely reported by the destination.

However, it is interesting to look at certain specific patterns observed, because the strength of this linkage (observed through frequencies in this case) is not uniform among brands. When considering the USA brands only, indeed, they explained the USA as the first market for the branded hotel just in $21 \%$ of cases, and as second market as $11 \%$ of cases. This was much less than what accounted by the French brands, recording $59 \%$ as first market and $24 \%$ as second market. While Spanish brands accounted $68 \%$ of their hotels having Spain as first market and $24 \%$ as second market.

\section{Conclusions}

In this study, we investigated the influence of brands country-of-origin effect on demand for hotels. Beyond providing evidence on what, to a large extent, has been a postulate in the hospitality literature so far, that is, the value of brands in terms of commercial impact, we contributed in terms of how the brand impact sales.

Looking at results with the hotel chains' eyes, conclusions are evident. Since brand image is a consequence of previous experience with service, of advertisement and word of mouth, of personal needs (i.e., cognitive and subjective sources), difficulty exists for multinational companies to cope with the coherence of these sources. For a hotel chain the main purpose of its brand management policy is to bring the three layers of the image closer, in order to reduce the gap existing between reality and perception and to allow a better sale of products (Radulescu \& Hudea, 2018), taking into account also that the brand's $\mathrm{COO}$ has effects on its international presence.

Looking at results with the hotel owner/developer's eyes, the research made clear that choosing a certain brand asks for a specific ex-ante evaluation: where is it from? Does it bring to the hotel the same market that the destination (already well) attracts? As opposite, is it a market that cannot be attracted because of the destination? Is it a market on which the hotel performs already well, so that the affiliation will bring a limited contribution to overall sales?

These analyses are obviously in the levers of hotel developers and hotel managers, for contract management opportunities, while within franchising this con- 
clusion is harder to take due to the often-practiced dual configuration of distribution (Chu \& Yoon, 2019). For equity-based business models, such as lease and direct ownership (Contractor et al., 1998), hotel chains will as opposite consider their potential ability to bring new markets to the destination where their $\mathrm{COO}$ market is yet unexplored or limited.

\section{References}

Bustamante J.C. (2019). Intellectual property rights as branding services for exports value-adding: an analysis of Chile-s -Sello de Origen- programme. International Journal of Intellectual Property Management, 9(3/4), 315-341.

Carvell, S. A., Canina, L., \& Sturman, M. C. (2016). A comparison of the performance of brand-affiliated and unaffiliated hotel properties. Cornell Hospitality Quarterly, 57(2), 193-201.

Hsu, C. H. C. (2014). Brand evaluation of foreign versus domestic luxury hotels by Chinese travelers, Journal of China Tourism Research, 10(1), 35-50, DOI: 10.1080/19388160.2013.870505

Chen J. J., \& Dimou, I. (2005). Expansion strategy of international hotel firms. Journal of Business Research 58(12), 1730-1740

Chen, L. F. (2019). Hotel chain affiliation as an environmental performance strategy for luxury hotels. International Journal of Hospitality Management, 77, $1-6$.

Chiang L. L., \& Yang C. (2018). Does country-of-origin brand personality generate retail customer lifetime value? A Big Data analytics approach. Technological Forecasting and Social Change, 130, 177-187

Chu Y., \& Yoon W. (2019). The imprinting effect of initial conditions on the configuration of dual distribution in franchising companies. Journal of Innovation \& Knowledge, 1-4. https://doi.org/10.1016/j. jik.2019.08.005

Contractor F., \& Kundu, S. (1998). Modal choice in a world of alliances: Analyzing organisational forms in the international hotel sector. Journal of International Business Studies, 29(2), 325-358.

Enz, C. A., \& Canina, L. (2011). A comparison of the performance of independent and franchise hotels: The first two years of operation. Cornell Hospitality Report, 11(21), 6-13.

Gomez-Suarez M., Quinones M., \& Yague M. (2019). How individual value structures shape smart shopping experience and brand choices: an international perspective. European Journal of International Management, 13(4), 515-532.

Hanson, B., Mattila, A. S., O’Neill, J. W., \& Kim, Y. (2009). Hotel rebranding and rescaling: Effects on financial performance. Cornell Hospitality Quarterly, 50(3), 360-370

Ingram, P. (1996). Organisational form as a solution to the problem of credible commitment: the evolution of naming strategies among U.S. hotel chains. Strategic Management Journal, 17(S1), 85-89.

Israeli, A. A. (2002). Star rating and corporate affiliation: their influence on room price and performance of hotels in Israel. Hospitality Management, 21(4), 405-424.

Ivanov, S., \& Ivanova M. (2016). Do hotel chains stimulate globalisation? Tourism Management Perspectives, 19(A), 102-108.

Keller, L. M. (2002). Branding and brand equity. In B. A. Weitz, \& R. Wensley (Eds.), Handbook of marketing (pp. 44-61). Sage.

Lee, S., Oh. Haemoon, \& Hsu, C. H. (2017). Countryof-operation and brand images: evidence from the Chinese hotel industry. International Journal of Contemporary Hospitality Management, 29(7), 1814-1833.

Leroux E., \& Pupion P.C. (2018). Factors of adoption of eco-labelling in hotel industry. Technological Forecasting and Social Change, 129, 194-209

Ma, Z., Novoselov, K. E., Zhou, K., \& Zhou, Y. (2019). Managerial academic experience, external monitoring, and financial reporting quality. Journal of Business Finance \& Accounting, 46(7-8). 843-878.

Mathews, V. E. (2000). Competition in the international hotel industry. International Journal of Contemporary Hospitality Management, 12(2), 114-118.

O’Neill, J. W., \& Carlbäckb M. (2011). Do brands matter? A comparison of branded and independent hotels' performance during a full economic cycle. International Journal of Hospitality Management, 30(3), 515-521.

O’Neill, J. W., \& Wang, H. (2008). International hotel development: A study of potential franchisees in China. International Journal of Hospitality Management, 27(3), 325-336.

O’Neill, J. W., \& Mattila, A. S. (2006). Strategic hotel development and positioning: The effect of revenue drivers on profitability. Cornell Hotel and Restaurant Administration Quarterly, 47(2), 146-54.

O'Neill, J. W., \& Xiao, Q. (2006). The role of brand affiliation in hotel market value. Cornell Hotel and Restaurant Administration Quarterly, 47(3), 210-223. 
O’Neill, J. W., Hanson, B., \& Mattila, A. S. (2008). The relationship of sales and marketing expenses to hotel performance in the United States. Cornell Hospitality Quarterly, 49(4), 355.

O’Neill, J. W., \& Mattila, A. S. (2010). Hotel brand strategy. Cornell Hospitality Quarterly, 51(1), 27-34.

Pappu R., Genevieve P., Cooksey R. (2006). Consumerbased brand equity and country-of-origin relationships: Some empirical evidence. European Journal of Marketing 40(5/6), 696-717.

Radulescu C., \& Hudea O. S. (2018). Econometric modelling of the consumer's behaviour in order to develop brand management policies. Economic Research-Ekonomska Istraživanja. 31(1), 576-591.

Revilla- Camacho M., Rey-Moreno M., Gallego A., \& Casanueva C. (2019). A resource generator methodology for hotels. Journal of Innovation \& Knowledge. 4 (2), 78-87.

Ribaudo G., Moccia S., Orero-Blat M., \& PalaciosMarques D. (in press). Comparing chains versus independent hotels based on international sales: an exploratory study. Economic Research - Ekonomska Istraživanja.

Ribaudo, G., \& Domeniconi, S. (2014). The penetration of international hotel chains in Italy: evidence from an updated census; Review of Business, 34(1), 5-19.

Suhartanto D. (2011). Hotel brand of origin: Do guests perceive service differences? Journal of Tourism, Hospitality \& Culinary Arts, 3(3), 1-24

Wang, X., Sun, J., \& Wen, H. (2019). Tourism seasonality, online user rating and hotel price: A quantitative approach based on the hedonic price model. International Journal of Hospitality Management, 79, 140-147. doi:10.1016/j.ijhm.2019.01.007

Whitla, P., Walters, G. P., \& Davies, H. (2007). Global strategies in the international hotel industry. Hospitality Management, 26(4), 777-792. 